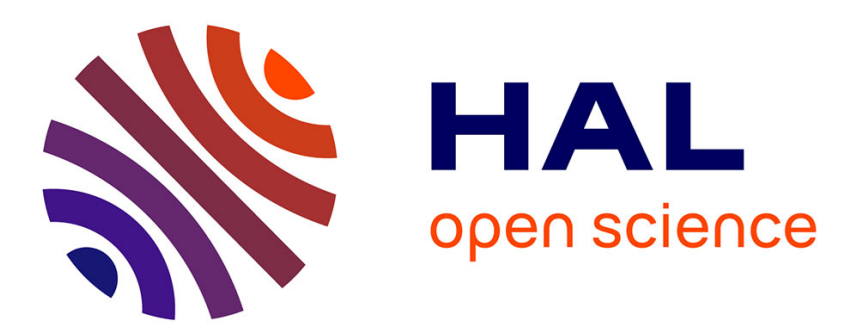

\title{
Differentiation of PC12 cells expressing estrogen receptor alpha: a new bioassay for endocrine-disrupting chemicals evaluation
}

Denis Habauzit, François Ferrière, Nadine Botherel, Gilles Flouriot, Farzad

Pakdel, Christian Saligaut

\section{To cite this version:}

Denis Habauzit, François Ferrière, Nadine Botherel, Gilles Flouriot, Farzad Pakdel, et al.. Differentiation of PC12 cells expressing estrogen receptor alpha: a new bioassay for endocrine-disrupting chemicals evaluation. Chemosphere, 2014, 112, pp.240-247. 10.1016/j.chemosphere.2014.03.101 . hal-01063907

\section{HAL Id: hal-01063907 https://hal.science/hal-01063907}

Submitted on 26 Sep 2014

HAL is a multi-disciplinary open access archive for the deposit and dissemination of scientific research documents, whether they are published or not. The documents may come from teaching and research institutions in France or abroad, or from public or private research centers.
L'archive ouverte pluridisciplinaire HAL, est destinée au dépôt et à la diffusion de documents scientifiques de niveau recherche, publiés ou non, émanant des établissements d'enseignement et de recherche français ou étrangers, des laboratoires publics ou privés. 
1 Differentiation of PC12 cells expressing estrogen receptor alpha: a new 2 bioassay for endocrine-disrupting chemicals evaluation

3 Denis Habauzit ${ }^{1}$, François Ferrière ${ }^{1}$, Nadine Botherel ${ }^{1^{*}}$, Gilles Flouriot ${ }^{1}$, Farzad 4 Pakdel $^{\mathbf{1}}$, Christian Saligaut ${ }^{1}$.

$5{ }^{1}$ Institut de Recherche en Santé Environnement et Travail (IRSET), INSERM U1085, Equipe 6 TREC, Université de Rennes 1, SFR Biosit, Rennes, France

7

8

9 Correspondence

10 Dr Denis Habauzit

11 Dr Farzad Pakdel

12 IRSET, Institut de Recherche en Santé, Environnement et Travail; Biosit; Equipe 13 "TREC"- bât 13, Université de Rennes 1; Campus de Beaulieu; 263 Avenue du Général 14 Leclerc; CS 74205; 35042 RENNES cedex, France

15 Phone: +33- 223236132 / +33- 223235132

17 E-mail: denis.habauzit@univ-rennes1.fr

18 Alternative E-mail: farzad.pakdel@univ-rennes1.fr

$19 *$ Present address: IGDR, Institute of Genetic and Development of Rennes; Université de 20 Rennes 1, Biosit, Rennes, France 


\section{ABSTRACT}

Xeno-estrogens, a class of endocrine disrupting chemicals (EDCs), can disturb estrogen receptor-dependent pathways involved in differentiation, proliferation or protection. Multiple methods have been developed to characterize the disturbances induced by EDCs in different cells or organs. In this study we have developed a new tool for the assessment of estrogenic compounds on differentiation. For this purpose we used the global model of NGFinduced neurite outgrowth of a pseudoneuronal PC12 cell line stably transfected with estrogen receptor alpha (PC12 ER). This new test evidences a new selectivity in which estradiol, genistein and 4-hydroxytamoxifen increased the NGF-induced neurite outgrowth of PC12 ER cells in a dose-dependent manner. In contrast, the strong estrogen agonist $17 \alpha-$ ethynylestradiol, the strong antagonist raloxifene and the agonist bisphenol A were unable to modify the neuritogenesis of PC12 ER cells. Therefore, the analysis of neuritogenesis in PC12 ER cells constitutes a complementary tool for the characterization of xeno-estrogen activity and also serves as a basis for further studies focusing on the mechanisms of EDCs in a neuronal context. Moreover, this test constitutes an alternative to animal testing.

7 differentiation. 


\section{INTRODUCTION}

It is known that estradiol (E2) acts on the reproductive system. However, it also has numerous actions on non-reproductive tissues such as bone, the cardiovascular system, the brain and the immune system (Turgeon et al., 2006). Several studies have reported that the actions of endogenous estrogens could be disrupted by pollutants, particularly xeno-estrogens, a family among endocrine-disrupting chemicals (EDCs) (Colborn et al., 1993; Guillette et al., 1994; Toppari et al., 1996). The primary environmental problem is that EDCs are widely dispersed in surface water (Campbell et al., 2006) throughout the world and the detected concentrations are mainly linked to waste water treatment plan that is not efficient enough to remove the overall compounds (Hamid and Eskicioglu, 2012). Their presence in environment constitutes a risk for Human and wildlife. In this context, the European Parliament has recently voted the inclusion in the list of priority substances of the Water Framework Directive, two well-known estrogenic compounds: E2 and 17 $\alpha$-ethynylestradiol (EE2), being used as pharmaceuticals (European Parliament News, 2012). These two compounds are present in environment at ng/L and ng/g in river and sediment (Huang et al., 2013; Leusch et al., 2013; Esteban et al., 2014). Therefore, several in vivo and in vitro methods have been developed to characterize the response of E2 as well as of other EDCs (Andersen et al., 1999; Kerdivel et al., 2013). In vivo methods utilize different species to study the different physiological functions of estrogens. For example, uterotrophic growth has been studied in rodents (Odum et al., 1997), vitellogenin expression has been investigated in rainbow trouthepatocytes (Flouriot et al., 1995; Sumpter and Jobling, 1995) or modification of life cycle was assessed in zebrafish (Micael et al., 2007). In vitro approaches were used to investigate the subcellular effects of E2 and EDCs that are mediated by estrogen receptor (ER)-dependent mechanisms, particularly transcriptional or membrane-initiated mechanisms (Mendelsohn, 2000; Edwards, 2005). 
Transcriptional studies primarily utilize in vitro short-term assays with reporter genes under the control of consensus sequences in their promoters, such as the estrogen response element (ERE)(Petit et al., 1995; Arnold et al., 1996; Andersen et al., 1999; Balaguer et al., 1999), the AP1- or SP1-binding sites(Fujimoto et al., 2004; Schreihofer, 2005). In parallel, other in vitro approaches were used to study the global cellular effects of EDCs. For instance, using the EScreen assay, studies report the proliferative effects of EDCs on ER positive breast cancer cells (Soto et al., 1992; Villalobos et al., 1995; Andersen et al., 1999). If xeno-estrogens have strong proliferative effects, they may also induce differentiating effects on certain tissues such as uterus, blood vessels, heart, bone and brain (Turgeon et al., 2006). With regard to the brain, many in vivo and in vitro studies have reported a role for E2 in brain protection and functioning (for review see Habauzit et al. 2011); however, there is no test currently available to assess the differentiating effects of EDCs in a neuronal context alternative to animal model. The PC12 cell line is derived from rat pheochromocytoma, a tumor arising from the adrenal medulla(Greene and Tischler, 1976) and is highly regarded among the in vitro neuronal cell models. Thus many studies have investigated the mechanisms of neurodegeneration/neuroprotection, in relation notably with Parkinson's disease, by determination in PC12 cells of the biosynthesis and release of catecholamine (Kumar et al., 1998; Yoneda et al., 2003; Ando et al., 2013), the modulation of redox activity (Shearman et al., 1994; Vimard et al., 2011). Other studies have investigated the mechanisms of differentiation, using the capacity to extend neurites when treated with nerve growth factor NGF (Gollapudi and Oblinger, 2001). Moreover the ability of PC12 cells to take into account the dependence on the ER status has also been reported: we previously demonstrated that the stable transfection of PC12 cells with ER $\alpha$ was able to modify differentiation (neurite outgrowth) or survival in the presence or not of the natural hormone E2 (Merot et al., 2005; Merot et al., 2009; Ferriere et al., 2013). 
In this study, our objective was to develop a new tool for the evaluation of the EDC differentiating effect. In this way the EDC effect was evaluate in the context of undifferentiated / differentiated PC12 cells mainly by the evaluation of their ability to act on the classical estrogenic targets: transcription and differentiation. We used the following pharmaceutical products: $17 \alpha$-ethynylestradiol (EE2), which is widely used for birth control (Lobo and Stanczyk, 1994); raloxifene (Ral) and 4-hydroxytamoxifen (4-OHT), which are two selective estrogen receptor modulators (SERMS) that display varying degrees of agonist or antagonist activities depending on the cellular context (Ho and Liao, 2002); the industrial product bisphenol A (BPA), which is a plasticizer and one of the most common EDCs (Willhite et al., 2008) and the clinically relevant phytoestrogen genistein (Gen), which is a plant-derived isoflavone (Polkowski and Mazurek, 2000). The concentrations of compounds used in this study were previously demonstrated to be near the physiologically active concentrations and near the concentration levels found in environment and/or plasma (Habauzit et al., 2011; Waye and Trudeau, 2011). Here, we report that the determination of neuritogenesis in PC12 ER positive cells constitutes a new tool for screening purposes as this technique provides information that are complimentary to other global bioassays based on cellular proliferation or to short-term subcellular analysis. The determination of neuritogenesis could also be a basis for further studies focusing on the mechanisms of EDCs in a neuronal context, which is currently poorly documented.

\section{MATERIALS AND METHODS}

\subsection{Materials}

The following reagents were purchased as powder from Sigma Aldrich (St. Louis, MO): E2, EE2, Gen, 4-OHT, Ral, BPA that were solubilized in ethanol or DMSO and then 
prepared by serial dilutions. No differences were observed between EtOH and DMSO on nerve growth factor (NGF) induced PC12differentiation (data not shown). The final vehicle concentration was $0.1 \%$ in the culture medium. Recombinant NGF was prepared according supplier information (Sigma Aldrich, St. Louis, MO). The antibody raised against ER $\alpha \mathrm{C}$ terminal (HC-20) was purchased from Santa Cruz Biotechnology (Santa Cruz, CA). The antibody raised against $\beta$-actin (AC-15) was purchased from Sigma Aldrich (St. Louis, MO).

\subsection{Plasmids}

The ER $\alpha$ cDNA, ERE-TK-Luc and CMV- $\beta$-Gal reporter plasmids were previously described (Flouriot et al., 2000; Metivier et al., 2002). The SP1 reporter plasmids were obtained from Panomics (Panomics Inc., Fremont, CA).

\subsection{Transcriptional activity of ER in undifferentiated and differentiated PC12 cells}

PC12 control and PC12 ER cells are naive PC12 cell lines that were transiently transfected respectively with the empty vector named pCR3.1 or with thepCR3.1 plasmid in which is integrated the coding sequence for full length Estrogen Receptor alpha (pCR3.1 $\mathrm{ER} \alpha$ ). These transient plasmid transfections were used in order to distinguish the ER dependent from ER independent EDCs transcriptional activities. These transcriptional activities were determined on two ER transcriptional pathways: - an ER direct interaction with DNA through ER/estrogen response element interaction (ERE consensus sequence integrated in plasmid containing luciferase as indicator of the compounds effects, ERE-TKLuc) - an ER indirect interaction through the ER/specific factor 1 that binds with the SP1 consensus DNA sequence (SP1 consensus sequence integrated in plasmid containing luciferase as indicator of the compounds effects, SP1-Luc). The plasmid CMV- $\beta$-gal was used for the normalization of the efficiency of the transient transfection, and the cytomegalovirus 
promoter led the compound independent expression of the $\beta$-galactosidase enzyme. Briefly, transient transfections of wild-type PC12 cells were performed in 24-well plates using the JetPEI transfection reagent (Polyplus transfection, Saint Quentin Yvelines France). One hour prior to transfection, the standard culture medium was replaced with phenol red-free DMEMF12 containing $2 \%$ charcoal-stripped serum composed by $1.6 \%$ charcoal-stripped fetal calf serum and $0.4 \%$ charcoal-stripped horse serum. The cells were then transfected for 12 hours with a DNA mixture containing the expression vectors (100 ng per well) ERE-TK-Luc or SP1-Luc together with CMV- $\beta$-Gal as the internal control (100 ng per well) and either the expression vector pCR3.1 or pCR3.1 ER $\alpha$ (50 ng per well). The total plasmid amount was 250 ng/well. After washing with PBS, different estrogenic compounds and/or Nerve growth factor (NGF; that initiates the PC12 cells neurite outgrowth) were added to the cells for 30 hours in DMEM-F12 containing $2 \%$ charcoal-stripped serum containing both fetal calf and horse serum. Cells were lysed with luciferase assay system with reporter lysis buffer (Promega, Madison). The reporter gene activity was quantified from the luciferase activity with Veritas Luminometer (Turner biosystems) and then the absorbance of the $\beta$ galactosidase activity was determined with iMark microplate reader (Biorad). The luciferase activity was then normalized by $\beta$-galactosidase activity. The fold of induction was finally determined by the normalization of tested compound on the PC12 control (+/- ER) with ethanol alone or with ethanol and NGF co-treatment, considered as reference compound (Flouriot et al., 2000).

\subsection{Generation of stable PC12 ERa clones}

Stable PC12 clones (PC12 control and PC12 ER) were previously obtained after transfection of wild-type PC12 cells with the expression vectors, empty pCR3.1 or pCR3.1 ER $\alpha$ containing the coding region cDNA of full length ER $\alpha$. The stable transfections were 
165

166

167

168

169

170

171

172

173

174

175

176

177

178

179

180

181

182

183

184

185

186

187

188

189

performed on PC12 cells, using the FuGENE6 reagent (Roche Diagnostics, Bâle, Switzerland). pCR3.1 plasmid also contains the resistance gene for geneticin antibiotics (G418, Invitrogen). The transfected cells, PC12 control clones (pCR3.1 empty) or PC12 ER (pCR3.1 ER $\alpha$ ) clones were selected with $800 \mu \mathrm{g} / \mathrm{ml}$ of G418 for 1 month (Merot et al., 2005). The PC12 cells were then routinely cultured in phenol red-free DMEM/F12 medium (Sigma) containing $8 \%$ and $2 \%$ charcoal-stripped fetal calf and horse serum, respectively (FCS; Biowest and Life Technologies, Cergy Pontoise, France) with $400 \mu \mathrm{g} / \mathrm{ml}$ of G418 antibiotics treatment in order to keep stably transfected cell selection. The ER $\alpha$ expression was verified in the PC12 control and PC12 ER clones by western blot analysis (Fig. 3B).

\subsection{Determination of ER $\alpha$-dependent proliferation of PC12 clones}

PC12 control clones and PC12 ER $\alpha$ clones were plated at $10^{4}$ cells per well on 24wells plate in phenol red-free DMEM/F12 medium (Gibco, Life Technologies, Cergy Pontoise, France) containing 5\% charcoal-stripped fetal calf (Biowest, Nuaille, France). 24 hours later, ethanol or different concentrations of E2 were added. The medium was renewed every 2 days. The proliferation test was stopped at day 5 by trypsination and then $100 \mu$ of fresh medium were added. Cells were then counted with malassez counting chamber. In order to verify our result and to assess the molecules effects a second proliferation test was performed. Cells were seeded onto 96 -well plates at $2 \times 10^{3}$ cells per well in phenol red-free DMEM/F12 containing 10\% of serum (Horse and calf). Twenty-four hours later, cells were transferred into phenol red-free DMEM/F12 containing either 5\% of charcoal stripped FCS (Sigma-Aldrich) for 24 hours. Then cells were treated with EtOH, E2 and others molecules for 7 days. The treatment was renewed every two days. At the end of the experiment, relative cell number was then assessed by quantification of cellular ATP content (ViaLight HS kit, Lonza). 
2.6. Determination of ER $\alpha$-dependent neurite outgrowth of PC12 cells

PC12 control and PC12 ER clones, plated at a density of $4 \times 10^{4}$ cells/well in 12-well

193

194

195

196

197

198

199

200

201

202

203

204

205

206

207

208

plates, were transferred to phenol red-free DMEM/F12 medium containing $2 \%$ charcoalstripped serum (1.6\% charcoal-stripped fetal calf serum and $0.4 \%$ charcoal-stripped horse serum) and then treated with $5 \mathrm{ng} / \mathrm{mL}$ NGF and/or EtOH, E2, EE2, Gen, 4-OHT, Ral and BPA at different concentrations. Sixty hours later, the differentiation of PC12 cells was scored as previously described (Merot et al., 2005). Briefly, the cells with at least one neurite with a length greater than one cell body were scored on at least 30 fields (10 fields x 3 separate experiments) under light microscopy. Results were expressed as the mean ratio of differentiating / total cells for each field. Secondly, the ratio adherents' cells / total cells was also calculated for each experimental condition.

\subsection{Statistical analysis}

The statistical analyses were performed by an analysis of variance followed by analysis of individual group differences using the Statview 5.0 software (SAS Institute Inc., Cary, NC). One-way analysis of variance (ANOVA) was used to determine the effects of estrogenic compounds on transcription (for more details see figure 1) or on neuritogenesis (for more details, see figure 4). Moreover a two-way analysis (two-AOV) was used to determine possible interactions between 2 variables: 1) interaction between effects of NGF and effects of estrogenic compounds on transcription.

\section{RESULTS}

\subsection{Transcriptional activity of EDCs in undifferentiated and differentiated PC12 cells}


We evaluated the estrogenic activities of classical estrogenic compounds on the transcriptional activity through ERE and SP1 reporter assay in a context of undifferentiated or

differentiated cells. In this way these activities were evaluated in PC12 cells treated or not with NGF. As expected, in the PC12 control cells (ER negative), the ERE-TK activity was not modified by either E2 or by the EDCs in the presence or in the absence of NGF treatment (Fig. 1A). By contrast, in the PC12 cells transiently transfected with ER $\alpha$, the compounds E2, Gen, EE2 and BPA increased the ERE-TK transcriptional activity, whereas 4-OHT and Ral decreased it whatever the NGF status. Both of these effects occurred in a dose-dependent manner (Fig. 1B). In the ER negative cells, higher concentrations of BPA and 4-OHT slightly decreased the SP1-Luc activity (Fig. 2A). SP1 luciferase activity was regulated in ER dependent manner by the estrogenic compounds. Indeed, E2, Gen, EE2, 4-OHT and BPA upregulated the SP1 reporter gene transcriptional activity in the PC12 ER cells in the presence or not of NGF (Fig. 2B). No significant interaction was identified following a 2-way ANOVA analysis between the treatments with EDCs and NGF for both ERE- and SP1- dependent transcription.

3.2. E2 and EDC promote a new selectivity on NGF-induced neurite outgrowth of PC12 ER clones

The dose-related neuritogenic effects of estradiol or different EDCs were determined on PC12 cells that were stably transfected with either pCR3.1 ERoor the empty vector, pCR3.1. Treatment with NGF $(5 \mathrm{ng} / \mathrm{mL})$ for $60 \mathrm{~h}$ provoked the neurite outgrowth of PC12 control and PC12 ER clones (Fig. 3A). The expression of ER in PC12 ER cells was confirmed by Western-Blot (Fig. 3B).

E2 $\left(10^{-9}\right.$ and $\left.10^{-8} \mathrm{M}\right)$ significantly increased the NGF-inducedneurite extension of the PC12 ER clones but not the PC12control clones (Fig. 4A). Gen (concentrations from $10^{-8}$ to 
$10^{-6} \mathrm{M}$ ) and 4-OHT (concentrations from $10^{-8}$ to $10^{-6} \mathrm{M}$ ) also increased the NGFinducedneuritogenesis via an ER $\alpha$-dependent mechanism (Fig. 4B-C). By contrast, EE2, Ral and BPA did not have significant effects on PC12 ER clones treated with NGF (Fig. 4D-F). In the absence of NGF, the compounds E2, EE2, Gen, 4-OHT, Ral and BPA did not modify neurite outgrowth of both PC12 ER and PC12 control clones (data not shown). Only the highest concentration of Gen $\left(10^{-5} \mathrm{M}\right)$ inhibited the neurite outgrowth in both the control and PC12 ER clones treated with NGF (Fig. 4B) and also decreased the ratio adherent cells / total cells (respectively $32 \pm 8.5 \%$ and $33.5 \pm 12.5 \%$ for PC12 ER and PC12 control clones, when this ratio was near 1 for other conditions (data not shown)).

\section{DISCUSSION}

Many studies reported that estrogens display neuroprotective effects (for review, see Habauzit et al, 2011) in physiopathological context of brain ischemia or Alzheimer's disease. For instance E2 reduces in ER-dependent manner brain damage induced by cerebral occlusion (Dubal et al., 2001) or prevents hippocampal neurons (Miller et al., 2005) or PC12 cells (Ferriere et al., 2013) from apoptosis. Another target of estradiol in brain is neuronal extension (for review see Toran-Allerand et al., 1999). For instance, estradiol enhanced neurite proliferation in organotypic cultures of the newborn mouse forebrain (Toran-Allerand, 1980) and in preoptic area grafted into adult rat brain(Matsumoto et al., 1988). In cell lineage, it was recently shown that E2 and diethylstilbestrol (DES) were able to increase the NGF induced neurite outgrowth in PC12 cells (Merot et al., 2005; Merot et al., 2009; Habauzit et al., 2011). But there are lacks in the evaluation of classical estrogenic compounds effect on cell differentiation and there is no available simple and fast cellular method for the estrogenic compounds differentiating effect evaluation other than those requiring animal testing. 
Several in vitro assays have been developed to characterize the global and subcellular effects of EDCs (Andersen et al., 1999). Like E2, the effects of EDCs can be mediated by classical transcriptional mechanisms through ERs (Fujimoto et al., 2004), and a large number of in vitroshort-term tests were developed for this screening purpose. The majority of these tests were based on EDC-induced transcriptional activity in different cells, such as yeast (Petit et al., 1995) or mammalian cells, that were transiently transfected with reporter plasmids containing ERE (Andersen et al., 1999), SP1 or AP1 binding sites in their promoters (Safe, 2001; Fujimoto et al., 2004; Schreihofer, 2005). These ER-dependent transcriptional effects had not yet been extensively studied in the context of pseudoneuronal PC12 cells, which can be present at undifferentiated or differentiated states. We found that E2, Gen, EE2 and BPA increase the ERE-dependent transcriptional activity of both undifferentiated and differentiated PC12 cells, whereas 4-OHT and Ral decreased this activity. These respective full agonistic and repressive effects were previously reported for other cell lines (Petit et al., 1995; Andersen et al., 1999; Paris et al., 2002; Fujimoto et al., 2004; Schreihofer, 2005). The 4OHT and Ral activity in PC12 cells may be dependent upon the cellular context of these cells and changes in the conformation of the ligand binding domain affecting the interaction of ER with coactivators or repressors (Smith and O'Malley, 2004). The ERE-mediated transcriptional effects of 4-OHT and Ral, which were observed in PC12 cells and MCF7 cells, were undetectable in neuro2A cells (Schreihofer, 2005). These differences underline the SERMs activities of these compounds. We clearly distinguish the activity of E2 from those of SERMs such as 4-OHT to modulate ERE-dependent genes/promoter construct. That was not true when we studied the ability of ER/ SP1 complexe to modulate transcription. Indeed, E2, 4-OHT and BPA increased SP1-dependent transcriptional activity in PC12 cells transfected with ER $\alpha$, as previously reported in breast cancer cells cotransfected with a SP1 construct and wild-type ER $\alpha(\mathrm{Kim}$ et al., 2003; Safe and Kim, 2008; Wu et al., 2008).Gen, EE2 also 
increased SP1-dependent transcription effects. Only Ral had no effects. Interestingly, profiles were similarin the context of undifferentiated or differentiated pseudoneuronal PC12 ER cells. The global effects of EDCs are demonstrated primarily by the proliferation of ERpositive breast cancer cells, particularly MCF-7 (E-SCREEN) and T47D cell lines treated for 4 to 6 days(Soto et al., 1992; Villalobos et al., 1995; Andersen et al., 1999; Fujimoto et al., 2004; Habauzit et al., 2010). Indeed, if E2 effectively induces the proliferation of MCF7 and T47D cells at $10^{-12} \mathrm{M}-10^{-9} \mathrm{M}$, E2 had no effect on the proliferation of PC12 cells when it is tested in the same range of concentration in the present study (data not shown). Thus, the proliferation of PC12 cells cannot be considered as a valid model for the evaluation of the estrogenic effects of EDCs.

Xeno-estrogens can also mediate differentiation processes either in vivo or in vitro in tissues such as the reproductive tract (Steinmetz et al., 1998; Svechnikov et al., 2010) or the brain (Panzica et al., 2009; Habauzit et al., 2011). These effects are not well documented. The global model of PC12 cell neuritogenesis can provide interesting specific information in the context of neuronal differentiation. A dose-dependent and ER $\alpha$-dependent increase of the NGF-inducedneuritogenesis is observed in PC12 cells treated with E2. As previously reported (Gollapudi and Oblinger, 2001; Merot et al., 2005; Merot et al., 2009), E2 (10 ${ }^{-9}$ and $\left.10^{-8} \mathrm{M}\right)$ significantly increased the NGF-inducedneurite extension of the PC12 ER clones but not the PC12control ones (Fig. 4A).We find that among the EDCs, Gen and 4-OHT also display estrogenic effects in PC12 ER clones in a concentration range of $10^{-8} \mathrm{M}$ to10 $0^{-6} \mathrm{M}$. By contrast, $10^{-5} \mathrm{M}$ Gen decreases neuritogenesis, as previously reported for high concentrations of this compound (Bouron et al., 1999). This inhibition appears to be ER-independent and could be explained by a toxic effect of Gen at this concentration. Indeed, we observed a decrease of more than $60 \%$ of adherent cells treated with $10^{-5} \mathrm{M}$ Gen that could support this hypothesis. This effect has been already observed in rat primary cortical neurons (Linford et al., 2001). 
The selective activation of ER by ligands that is dependent upon the tissue environment is true for the SERMs, 4-OHT and Ral. For instance, both Ral and 4-OHT displayed an antiestrogenic activity in a proliferation assay of T47D cells(Habauzit et al., 2010), whereas the ER could not discriminate among chemicals with estrogenic or anti-estrogenic activitiesin the context of yeast (Petit et al., 1995).In vivo, both Ral and 4-OHT displayed cell-specific estrogenic agonist activity in the skeleton and antagonist activity in the breast (Cauley et al., 2001; Smith and O'Malley, 2004). However, Ral may lack the uterotrophic activity associated with tamoxifen (Delmas et al., 1997; Anthony et al., 2001). Like in the uterus, we found that Ral lacks in PC12 cells a neuritogenic activity compared with 4-OHT. However, Nilsen et al. demonstrated that Ral induced neurotrophic effects in PC12 ER positive cells (Nilsen et al., 1998). The opposite results could be explained by the experimental procedures and by the levels of ER $\alpha$ expressed in those cells. Indeed, Nilsen et al. induced ER $\alpha$ expression with a 2week NGF treatment, whereas we used the stable transfection of PC12 cells. BPA and EE2 are generally defined as estrogenic compounds. Concentration of BPA was found in several biological samples such as blood, milk and urine (Lee et al., 2013). BPA mimics E2 in numerous in vivo and in vitro studies in a concentration range of $10^{-9} \mathrm{M}$ to $10^{-5} \mathrm{M}$. For example, BPA induced cell proliferation in the uterus of ovariectomized rats in vivo, and its effects were nearly identical to those induced by E2 (Steinmetz et al., 1998). BPA did not modify neuritogenesis of PC12 ER clones, even at the highest concentrations used $\left(10^{-7} \mathrm{M}\right.$ and $10^{-6} \mathrm{M}$ ), whereas E2 and the well-established estrogenic compound diethylstilbestrol increased neuritogenesis at a concentration of $10^{-9} \mathrm{M}$ (Merot et al., 2009). In PC12 cells, only concentrations of BPA higher than $50 \mu \mathrm{M}$ had been reported to decrease viability and neurite extension via an ER-dependent mechanism(Lee et al., 2007). EE2 is a clinically relevant estrogenic compound that is more potent than E2 and is widely used for birth control (Lobo and Stanczyk, 1994). With regard to the subcellular or global cellular assays of estrogenicity, 
$10^{-10} \mathrm{M}$ to $10^{-9} \mathrm{M}$ EE2 can display strong estrogenic activity. It is verified using the EREdependent transcriptional activity in PC12 cells (present study) or in the global model of proliferation in T47D or MCF7 cells (Andersen et al., 1999; Habauzit et al., 2010). By contrast, EE2 did not modify PC12 neuritogenesis in the concentration range of $10^{-10} \mathrm{M}$ to $10^{-}$ ${ }^{7}$ M. Distinct biological cell-specific potencies of E2 and EE2 that are mediated by the ER are not usually reported. However, E2, but not EE2, induced ER-dependent NO synthesis and protection against oxidative stress in endothelial cell cultures (Andozia et al., 2010).

The effects of EDCs on ERE-, SP1-mediated transcription in undifferentiated and differentiated PC12 cells gave profiles that have been classically reported for other cell lines, especially for breast cancer cells. The global analysis of neuritogenesis in PC12 cells stably transfected with ER $\alpha$ has demonstrated a selectivity of the EDCs that is distinct from that observed for the subcellular bioassay of transcription. The effects of estrogens can be the result in neuronal cells of a tissue-specific complex interplay of the activation/inhibition of DNA binding-dependent, DNA binding-independent gene transcription but also membraneinitiated mechanisms (Habauzit et al. 2011). The pathways involved in the EDC-induced neuritogenesis in the PC12 ER clones could be different from those involved in the differentiation and proliferation of other cell lines and could be linked to the specific cellular context, especially the presence of specific transcription factors, coactivators and corepressors (Smith and O'Malley, 2004).

In the future, investigations into the mechanisms that sustain the effects of EDCs should integrate different approaches and interassay comparisons. As a result, the determination of neurite outgrowth of PC12 ER clones constitutes an original and complementary global bioassay for the characterization of xeno-estrogens. PC12 ER clones and cells expressing different deleted or mutated forms of ER $\alpha$ have been previously used to investigate subcellular ER-dependent mechanisms sustaining E2 activity (Merot et al., 2009). 
364 Thus, neuritogenic effects of E2 were suppressed in PC12 cells stably transfected with a DNA

365 binding domain deleted ER $\alpha$ (Merot et al., 2009). These different PC12 clones could also be 366 used to characterize the ER domains that are involved in the effects of EDCs. Moreover, these 367 PC12 clones provide the basis for further studies focusing on the effects of EDCs in the 368 specific context of brain development or diseases, which remain poorly documented.

371 Acknowledgements - This work was supported by grants from the Agence Nationale de la

372 Recherche (project NEED: CES 2008-011), CRITT-Santé Bretagne (contract: 08007968) and

373 INERIS (project NEMO: 189). We also thank CNRS, INSERM and the University of Rennes 3741 for supporting our research. 
Andersen, H.R., Andersson, A.M., Arnold, S.F., Autrup, H., Barfoed, M., Beresford, N.A., Bjerregaard, McLachlan, J., Moller, A., Nielsen, J.B., Olea, N., Oles-Karasko, A., Pakdel, F., Pedersen, K.L., Perez, P., Skakkeboek, N.E., Sonnenschein, C., Soto, A.M., et al., 1999. Comparison of short-term estrogenicity tests for identification of hormone-disrupting chemicals. Environ Health Perspect 107 Suppl 1, 89108.

Ando, K., Kudo, Y., Aoyagi, K., Ishikawa, R., Igarashi, M., Takahashi, M., 2013. Calmodulin-dependent regulation of neurotransmitter release differs in subsets of neuronal cells. Brain Res 1535, 1-13.

Andozia, M.B., Vieira, C.S., Franceschini, S.A., Torqueti Tolloi, M.R., Silva de Sa, M.F., Ferriani, R.A., 2010. Ethinylestradiol and estradiol have different effects on oxidative stress and nitric oxide synthesis in human endothelial cell cultures. Fertil Steril 94, 1578-1582.

Anthony, M., Williams, J.K., Dunn, B.K., 2001. What would be the properties of an ideal SERM? Ann N Y Acad Sci 949, 261-278.

Arnold, S.F., Robinson, M.K., Notides, A.C., Guillette, L.J., Jr., McLachlan, J.A., 1996. A yeast estrogen screen for examining the relative exposure of cells to natural and xenoestrogens. Environ Health Perspect 104, 544-548.

Balaguer, P., Francois, F., Comunale, F., Fenet, H., Boussioux, A.M., Pons, M., Nicolas, J.C., Casellas, C., 1999. Reporter cell lines to study the estrogenic effects of xenoestrogens. Sci Total Environ 233, 47-56.

Bouron, A., Becker, C., Porzig, H., 1999. Functional expression of voltage-gated $\mathrm{Na}+$ and $\mathrm{Ca} 2+$ channels during neuronal differentiation of PC12 cells with nerve growth factor or forskolin. Naunyn Schmiedebergs Arch Pharmacol 359, 370-377.

Campbell, C.G., Borglin, S.E., Green, F.B., Grayson, A., Wozei, E., Stringfellow, W.T., 2006. Biologically directed environmental monitoring, fate, and transport of estrogenic endocrine disrupting compounds in water: A review. Chemosphere 65, 1265-1280.

Cauley, J.A., Norton, L., Lippman, M.E., Eckert, S., Krueger, K.A., Purdie, D.W., Farrerons, J., Karasik, A., Mellstrom, D., Ng, K.W., Stepan, J.J., Powles, T.J., Morrow, M., Costa, A., Silfen, S.L., Walls, E.L., Schmitt, H., Muchmore, D.B., Jordan, V.C., Ste-Marie, L.G., 2001. Continued breast cancer risk reduction in postmenopausal women treated with raloxifene: 4-year results from the MORE trial. Multiple outcomes of raloxifene evaluation. Breast Cancer Res Treat 65, 125-134.

Colborn, T., vom Saal, F.S., Soto, A.M., 1993. Developmental effects of endocrine-disrupting chemicals in wildlife and humans. Environ Health Perspect 101, 378-384.

Delmas, P.D., Balena, R., Confravreux, E., Hardouin, C., Hardy, P., Bremond, A., 1997. Bisphosphonate risedronate prevents bone loss in women with artificial menopause due to chemotherapy of breast cancer: a double-blind, placebo-controlled study. J Clin Oncol 15, 955-962.

Dubal, D.B., Zhu, H., Yu, J., Rau, S.W., Shughrue, P.J., Merchenthaler, I., Kindy, M.S., Wise, P.M., 2001. Estrogen receptor alpha, not beta, is a critical link in estradiol-mediated protection against brain injury. Proc Natl Acad Sci U S A 98, 1952-1957.

Edwards, D.P., 2005. Regulation of signal transduction pathways by estrogen and progesterone. Annu Rev Physiol 67, 335-376.

Esteban, S., Gorga, M., Petrovic, M., Gonzalez-Alonso, S., Barcelo, D., Valcarcel, Y., 2014. Analysis and occurrence of endocrine-disrupting compounds and estrogenic activity in the surface waters of Central Spain. Sci Total Environ 466-467, 939-951.

$\begin{array}{lllll}\text { European } & \text { Parliament } & \text { News, } & \text { Available }\end{array}$ http://www.europarl.europa.eu/news/en/pressroom/content/20121126IPR56466/html/Surfacewaters-new-chemicals-added-to-EU-risk-list; last Ferriere, F., Habauzit, D., Pakdel, F., Saligaut, C., Flouriot, G., 2013. Unliganded Estrogen Receptor Alpha Promotes PC12 Survival during Serum Starvation. PLoS One 8, e69081. 
Flouriot, G., Brand, H., Denger, S., Metivier, R., Kos, M., Reid, G., Sonntag-Buck, V., Gannon, F., 2000. Identification of a new isoform of the human estrogen receptor-alpha (hER-alpha) that is encoded by distinct transcripts and that is able to repress hER-alpha activation function 1. Embo J 19, 4688-4700. Flouriot, G., Pakdel, F., Ducouret, B., Valotaire, Y., 1995. Influence of xenobiotics on rainbow trout liver estrogen receptor and vitellogenin gene expression. J Mol Endocrinol 15, 143-151.

Fujimoto, N., Honda, H., Kitamura, S., 2004. Effects of environmental estrogenic chemicals on AP1 mediated transcription with estrogen receptors alpha and beta. J Steroid Biochem Mol Biol 88, 53-59. Gollapudi, L., Oblinger, M.M., 2001. Estrogen effects on neurite outgrowth and cytoskeletal gene expression in ERalpha-transfected PC12 cell lines. Exp Neurol 171, 308-316.

Greene, L.A., Tischler, A.S., 1976. Establishment of a noradrenergic clonal line of rat adrenal pheochromocytoma cells which respond to nerve growth factor. Proc Natl Acad Sci U S A 73, 24242428.

Guillette, L.J., Jr., Gross, T.S., Masson, G.R., Matter, J.M., Percival, H.F., Woodward, A.R., 1994. Developmental abnormalities of the gonad and abnormal sex hormone concentrations in juvenile alligators from contaminated and control lakes in Florida. Environ Health Perspect 102, 680-688.

Habauzit, D., Boudot, A., Kerdivel, G., Flouriot, G., Pakdel, F., 2010. Development and validation of a test for environmental estrogens: Checking xeno-estrogen activity by CXCL12 secretion in BREAST CANCER CELL LINES (CXCL-test). Environ Toxicol 25, 495-503.

Habauzit, D., Flouriot, G., Pakdel, F., Saligaut, C., 2011. Effects of estrogens and endocrine disrupting chemicals on cell differentiation-survival-proliferation in brain: Contributions of neuronal cell lines. $J$ Toxicol Environ Health B Crit Rev 14, 300-327.

Hamid, H., Eskicioglu, C., 2012. Fate of estrogenic hormones in wastewater and sludge treatment: A review of properties and analytical detection techniques in sludge matrix. Water Res 46, 5813-5833. Ho, K.J., Liao, J.K., 2002. Non-nuclear actions of estrogen: new targets for prevention and treatment of cardiovascular disease. Mol Interv 2, 219-228.

Huang, B., Wang, B., Ren, D., Jin, W., Liu, J., Peng, J., Pan, X., 2013. Occurrence, removal and bioaccumulation of steroid estrogens in Dianchi Lake catchment, China. Environ Int 59C, 262-273.

Kerdivel, G., Habauzit, D., Pakdel, F., 2013. Assessment and molecular actions of endocrine-disrupting chemicals that interfere with estrogen receptor pathways. Int J Endocrinol 2013, 501851.

Kim, K., Thu, N., Saville, B., Safe, S., 2003. Domains of estrogen receptor alpha (ERalpha) required for ERalpha/Sp1-mediated activation of GC-rich promoters by estrogens and antiestrogens in breast cancer cells. Mol Endocrinol 17, 804-817.

Kumar, G.K., Overholt, J.L., Bright, G.R., Hui, K.Y., Lu, H., Gratzl, M., Prabhakar, N.R., 1998. Release of dopamine and norepinephrine by hypoxia from PC-12 cells. Am J Physiol 274, C1592-1600.

Lee, S.G., Kim, J.Y., Chung, J.Y., Kim, Y.J., Park, J.E., Oh, S., Yoon, Y.D., Yoo, K.S., Yoo, Y.H., Kim, J.M., 2013. Bisphenol A exposure during adulthood causes augmentation of follicular atresia and luteal regression by decreasing 17 beta-estradiol synthesis via downregulation of aromatase in rat ovary. Environ Health Perspect 121, 663-669.

Lee, Y.M., Seong, M.J., Lee, J.W., Lee, Y.K., Kim, T.M., Nam, S.Y., Kim, D.J., Yun, Y.W., Kim, T.S., Han, S.Y., Hong, J.T., 2007. Estrogen receptor independent neurotoxic mechanism of bisphenol A, an environmental estrogen. J Vet Sci 8, 27-38.

Leusch, F.D., Khan, S.J., Gagnon, M.M., Quayle, P., Trinh, T., Coleman, H., Rawson, C., Chapman, H.F., Blair, P., Nice, H., Reitsema, T., 2013. Assessment of wastewater and recycled water quality: A comparison of lines of evidence from in vitro, in vivo and chemical analyses. Water Res.

Linford, N.J., Yang, Y., Cook, D.G., Dorsa, D.M., 2001. Neuronal apoptosis resulting from high doses of the isoflavone genistein: role for calcium and p42/44 mitogen-activated protein kinase. J Pharmacol Exp Ther 299, 67-75.

Lobo, R.A., Stanczyk, F.Z., 1994. New knowledge in the physiology of hormonal contraceptives. Am J Obstet Gynecol 170, 1499-1507.

Matsumoto, A., Murakami, S., Arai, Y., 1988. Neurotropic effects of estrogen on the neonatal preoptic area grafted into the adult rat brain. Cell Tissue Res 252, 33-37. 
Mendelsohn, M.E., 2000. Nongenomic, ER-mediated activation of endothelial nitric oxide synthase: how does it work? What does it mean? Circ Res 87, 956-960.

Merot, Y., Ferriere, F., Debroas, E., Flouriot, G., Duval, D., Saligaut, C., 2005. Estrogen receptor alpha mediates neuronal differentiation and neuroprotection in PC12 cells: critical role of the A/B domain of the receptor. J Mol Endocrinol 35, 257-267.

Merot, Y., Ferriere, F., Gailhouste, L., Huet, G., Percevault, F., Saligaut, C., Flouriot, G., 2009. Different outcomes of unliganded and liganded estrogen receptor-alpha on neurite outgrowth in PC12 cells. Endocrinology 150, 200-211.

Metivier, R., Stark, A., Flouriot, G., Hubner, M.R., Brand, H., Penot, G., Manu, D., Denger, S., Reid, G., Kos, M., Russell, R.B., Kah, O., Pakdel, F., Gannon, F., 2002. A dynamic structural model for estrogen receptor-alpha activation by ligands, emphasizing the role of interactions between distant $A$ and $E$ domains. Mol Cell 10, 1019-1032.

Micael, J., Reis-Henriques, M.A., Carvalho, A.P., Santos, M.M., 2007. Genotoxic effects of binary mixtures of xenoandrogens (tributyltin, triphenyltin) and a xenoestrogen (ethinylestradiol) in a partial life-cycle test with Zebrafish (Danio rerio). Environ Int 33, 1035-1039.

Miller, N.R., Jover, T., Cohen, H.W., Zukin, R.S., Etgen, A.M., 2005. Estrogen can act via estrogen receptor alpha and beta to protect hippocampal neurons against global ischemia-induced cell death. Endocrinology 146, 3070-3079.

Nilsen, J., Mor, G., Naftolin, F., 1998. Raloxifene induces neurite outgrowth in estrogen receptor positive PC12 cells. Menopause 5, 211-216.

Odum, J., Lefevre, P.A., Tittensor, S., Paton, D., Routledge, E.J., Beresford, N.A., Sumpter, J.P., Ashby, J., 1997. The rodent uterotrophic assay: critical protocol features, studies with nonyl phenols, and comparison with a yeast estrogenicity assay. Regul Toxicol Pharmacol 25, 176-188.

Panzica, G.C., Mura, E., Miceli, D., Martini, M.A., Gotti, S., Viglietti-Panzica, C., 2009. Effects of xenoestrogens on the differentiation of behaviorally relevant neural circuits in higher vertebrates. Ann N Y Acad Sci 1163, 271-278.

Paris, F., Balaguer, P., Terouanne, B., Servant, N., Lacoste, C., Cravedi, J.P., Nicolas, J.C., Sultan, C., 2002. Phenylphenols, biphenols, bisphenol-A and 4-tert-octylphenol exhibit alpha and beta estrogen activities and antiandrogen activity in reporter cell lines. Mol Cell Endocrinol 193, 43-49.

Petit, F., Valotaire, Y., Pakdel, F., 1995. Differential functional activities of rainbow trout and human estrogen receptors expressed in the yeast Saccharomyces cerevisiae. Eur J Biochem 233, 584-592.

Polkowski, K., Mazurek, A.P., 2000. Biological properties of genistein. A review of in vitro and in vivo data. Acta Pol Pharm 57, 135-155.

Safe, S., 2001. Transcriptional activation of genes by 17 beta-estradiol through estrogen receptor-Sp1 interactions. Vitam Horm 62, 231-252.

Safe, S., Kim, K., 2008. Non-classical genomic estrogen receptor (ER)/specificity protein and ER/activating protein-1 signaling pathways. J Mol Endocrinol 41, 263-275.

Schreihofer, D.A., 2005. Transcriptional regulation by phytoestrogens in neuronal cell lines. Mol Cell Endocrinol 231, 13-22.

Shearman, M.S., Ragan, C.I., Iversen, L.L., 1994. Inhibition of PC12 cell redox activity is a specific, early indicator of the mechanism of beta-amyloid-mediated cell death. Proc Natl Acad Sci U S A 91, 1470-1474.

Smith, C.L., O'Malley, B.W., 2004. Coregulator function: a key to understanding tissue specificity of selective receptor modulators. Endocr Rev 25, 45-71.

Soto, A.M., Lin, T., Justicia, H., Silvia, R.M., Sonnenschein, C., 1992. An "in culture" bioassay to assess the estrogenicity of xenobiotics (ESCREEN). Chemically Induced Alterations in Sexual Development: The Wildlife/Human Connection (Colborn T, Clement CR, eds). Princeton, NJ:Princeton Scientific Publishing, 295-309.

Steinmetz, R., Mitchner, N.A., Grant, A., Allen, D.L., Bigsby, R.M., Ben-Jonathan, N., 1998. The xenoestrogen bisphenol $A$ induces growth, differentiation, and c-fos gene expression in the female reproductive tract. Endocrinology 139, 2741-2747. 
528 Sumpter, J.P., Jobling, S., 1995. Vitellogenesis as a biomarker for estrogenic contamination of the 529 aquatic environment. Environ Health Perspect 103 Suppl 7, 173-178.

530 Svechnikov, K., Izzo, G., Landreh, L., Weisser, J., Soder, O., 2010. Endocrine disruptors and Leydig cell 531 function. J Biomed Biotechnol 2010, 10.

532 Toppari, J., Larsen, J.C., Christiansen, P., Giwercman, A., Grandjean, P., Guillette, L.J., Jr., Jegou, B., 533 Jensen, T.K., Jouannet, P., Keiding, N., Leffers, H., McLachlan, J.A., Meyer, O., Muller, J., Rajpert-De 534 Meyts, E., Scheike, T., Sharpe, R., Sumpter, J., Skakkebaek, N.E., 1996. Male reproductive health and 535 environmental xenoestrogens. Environ Health Perspect 104 Suppl 4, 741-803.

536 Toran-Allerand, C.D., 1980. Sex steroids and the development of the newborn mouse hypothalamus and preoptic area in vitro. II. Morphological correlates and hormonal specificity. Brain Res 189, 413427.

Toran-Allerand, C.D., Singh, M., Setalo, G., Jr., 1999. Novel mechanisms of estrogen action in the brain: new players in an old story. Front Neuroendocrinol 20, 97-121.

Turgeon, J.L., Carr, M.C., Maki, P.M., Mendelsohn, M.E., Wise, P.M., 2006. Complex actions of sex steroids in adipose tissue, the cardiovascular system, and brain: Insights from basic science and clinical studies. Endocr Rev 27, 575-605.

Villalobos, M., Olea, N., Brotons, J.A., Olea-Serrano, M.F., Ruiz de Almodovar, J.M., Pedraza, V., 1995. The E-screen assay: a comparison of different MCF7 cell stocks. Environ Health Perspect 103, 844850. hydroperoxide in PC12 cells: protective role of thiol donors. J Biochem Mol Toxicol 25, 205-215. Waye, A., Trudeau, V.L., 2011. Neuroendocrine disruption: more than hormones are upset. J Toxicol Environ Health B Crit Rev 14, 270-291. Willhite, C.C., Ball, G.L., McLellan, C.J., 2008. Derivation of a bisphenol A oral reference dose (RfD) and drinking-water equivalent concentration. J Toxicol Environ Health B Crit Rev 11, 69-146. Wu, F., Khan, S., Wu, Q., Barhoumi, R., Burghardt, R., Safe, S., 2008. Ligand structure-dependent activation of estrogen receptor alpha/Sp by estrogens and xenoestrogens. J Steroid Biochem Mol Biol 555 110, 104-115. release by bisphenol-A in PC12 cells. J Neurochem 87, 1499-1508. 
562

563

564

565

566

567

568

569

570

571

572

573

574

575

576

577

578

579

580

581

582

583

584

585

\section{Figure Legends}

Fig. 1. The transcriptional effects of estrogenic compounds measured by the ERE-TK-Luc reporter assay in undifferentiated or differentiated PC12 cells. PC12 cells were transiently transfected with ERE-TK-Luc reporter gene together with CMV- $\beta$-Gal and the empty pCR3.1 plasmid (A) or the pCR3.1 plasmid encoding ER $\alpha$ (B). Twelve hours after transfection, the cells were differentiated or not with NGF $(5 \mathrm{ng} / \mathrm{mL})$ (respectively right and left panels) and treated with vehicle control ethanol $(\mathrm{EtOH})$ or $17 \beta$ estradiol $\left(\mathrm{E} 2: 10^{-9} \mathrm{M}\right)$, genistein (Gen: $10^{-}$ ${ }^{9} \mathrm{M}$ and $10^{-7} \mathrm{M}$ ), $17 \alpha$ ethynylestradiol (EE2: $10^{-9} \mathrm{M}$ and $10^{-7} \mathrm{M}$ ), 4-hydroxytamoxifen (4OHT: $10^{-9} \mathrm{M}$ and $10^{-6} \mathrm{M}$ ), raloxifen (Ral: $10^{-7} \mathrm{M}$ ), bisphenol A (BPA: $10^{-9} \mathrm{M}$ and $10^{-7} \mathrm{M}$ ) for $30 \mathrm{~h}$. The luciferase activities after E2 and EDCs treatments were expressed in reference (fold induction) to the luciferase activity measured in cells treated with EtOH (A and B). The data are the mean \pm SEM of four experiments. No significant interaction was identified following a 2-way ANOVA analysis of the EDC and NGF treatments. *, $P<0.05 ; * *, P<0.01$ and ***, $P<0.001$ : for the significant effects of the estrogenic compounds compared to the respective controls, which are the cells treated with EtOH +/- NGF.

Fig. 2. The transcriptional effects of estrogenic compounds measured by the SP1-luc reporter assay in undifferentiated or differentiated PC12 cells. PC12 cells were transiently transfected with SP1-Luc reporter gene together with CMV- $\beta$-Gal and the empty pCR3.1 plasmid (A) or the pCR3.1 plasmid encoding ER $\alpha$ (B). Cells were then differentiated or not with NGF and treated with control EtOH or E2, Gen, EE2, 4-OHT, Ral, BPA for 30 h (for more details, see Figure 1). 
586

587

588

589

590

591

592

593

594

595

596

597

598

599

600

601

602

603

604

Fig. 3. PC12 clones obtained after stable transfection. (A) PC12 cells stably transfected with pCR3.1 plasmid encoding ER $\alpha$ (PC12 ER clones) or the empty pCR3.1 plasmid (PC12 Control clones). The NGF treatment induces neurite outgrowth of both PC12 clones (lower panel). (B) ER $\alpha$ expression was controlled by western blot in PC12 clones that stably express $\mathrm{ER} \alpha(\mathrm{PC} 12 \mathrm{ER})$ or that do not express ER $\alpha$ (PC12 control), and the expression of $\beta$-Actin was used as internal control.

Fig. 4. Neuritogenic effects of estrogenic compounds in PC12 clones. Neurite outgrowth was induced by treatment with NGF $(5 \mathrm{ng} / \mathrm{ml})$ for 2 days in the PC12 clones that stably express ER $\alpha$ (PC12 ER) or not (PC12 control). Simultaneously with NGF, clones were treated with different concentrations of $17 \beta$ estradiol (A) and EDCs (B-F). The neurite outgrowth was quantified by scoring the ratio differentiated cells/undifferentiated cells for each microscopy field. Differentiated cells were ones that have at least one neurite that the length is greater than one cell body. For both PC12 control and PC12 ER clones, results were expressed in reference (fold induction) to the neurite outgrowth of differentiated cells treated with EtOH. *, $P<0.05 ; * *, P<0.01$ and $* * *, P<0.001$ : significant effects of the different concentrations of EDCs in reference with EtOH. The data are the mean \pm SEM of 30 to110 light microscopy fields. 
Fig 1

\section{ERE TK luc activity}

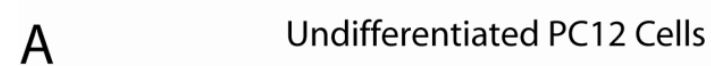

Differentiated PC12 Cells
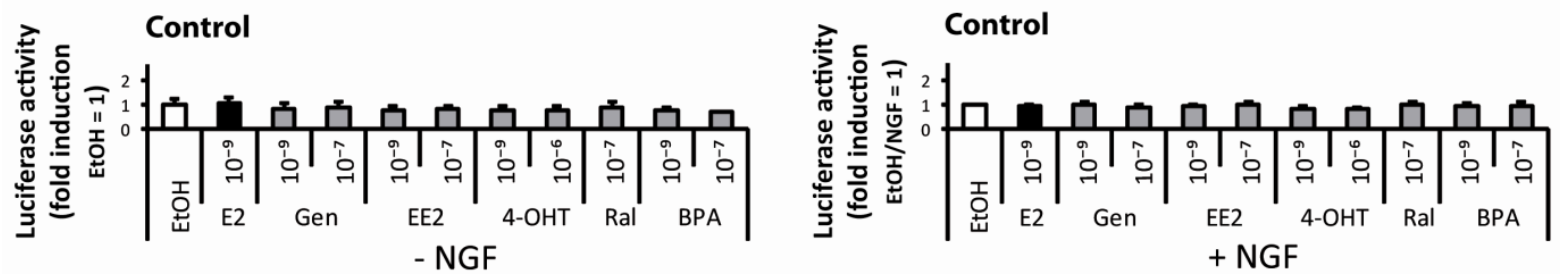

B
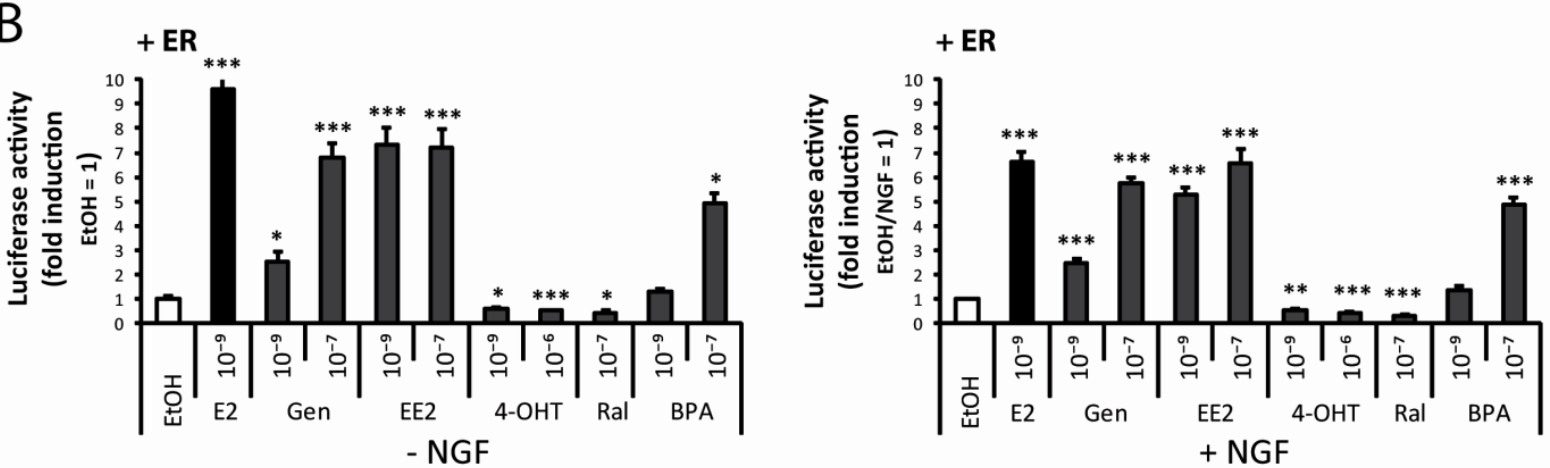

606 
Fig.2

\section{SP1 luc activity}

A

Undifferentiated PC12 Cells

Differentiated PC12 Cells
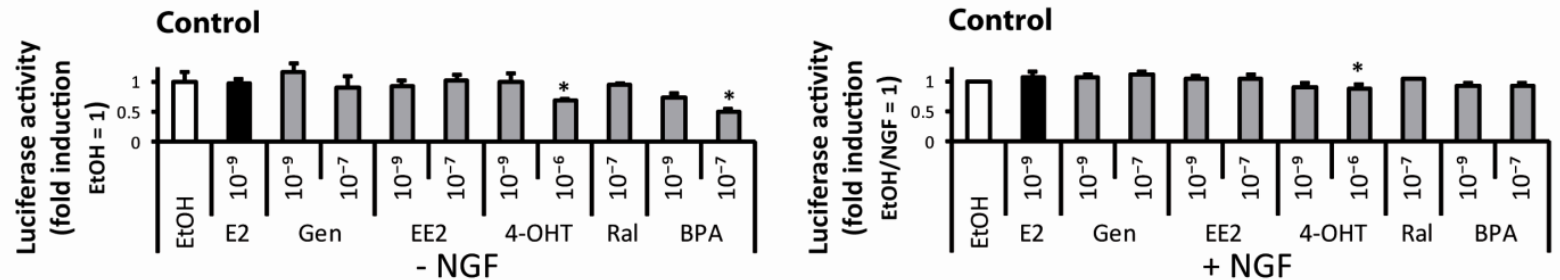

B
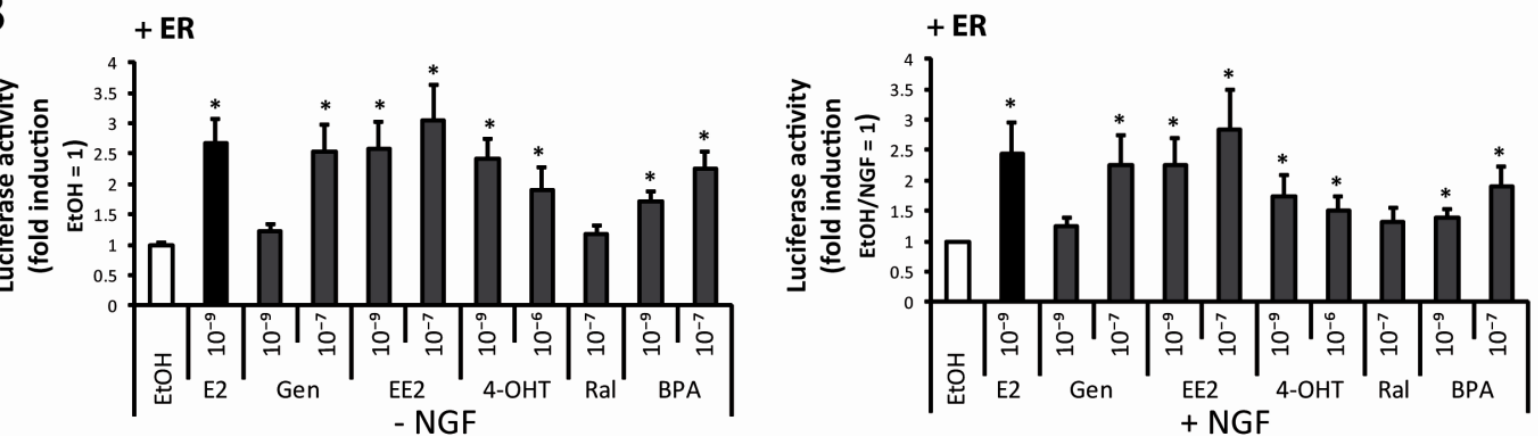

609 - NGF

610

611

612 
613 Fig. 3.

A

Undifferentiated PC12 Cells

Differentiated PC12 Cells
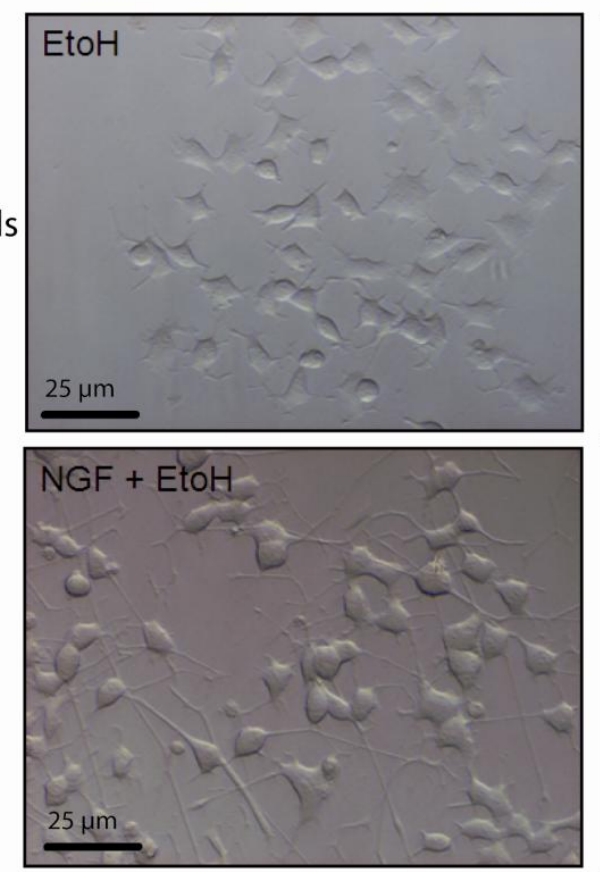

PC12 ER Clones

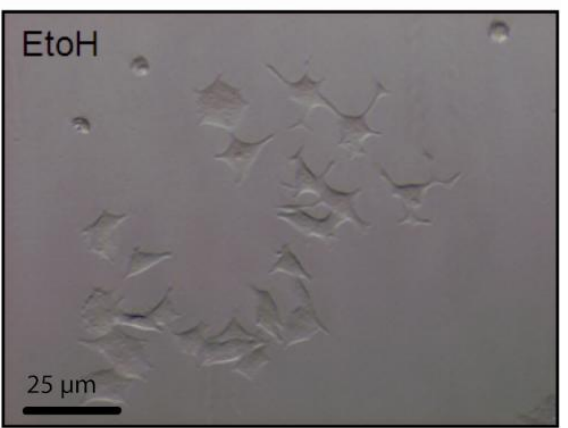

$\mathrm{NGF}+\mathrm{EtoH}$

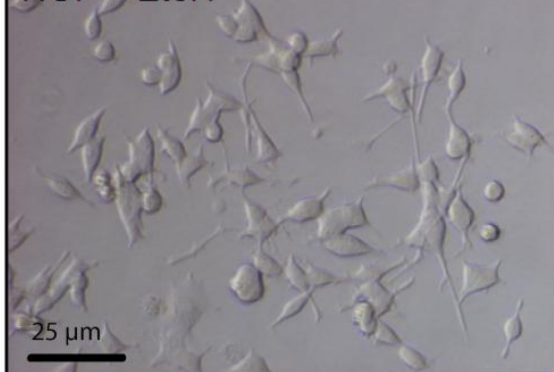

B

614

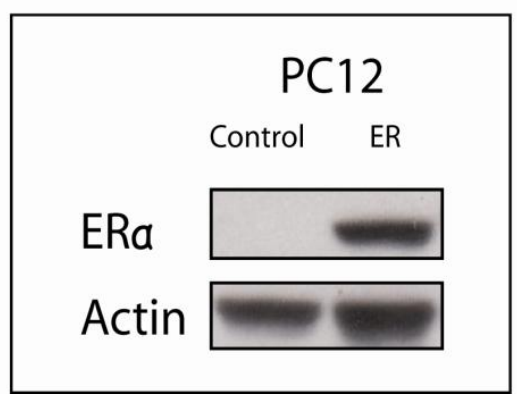

615

616

617 
Fig. 4.

A

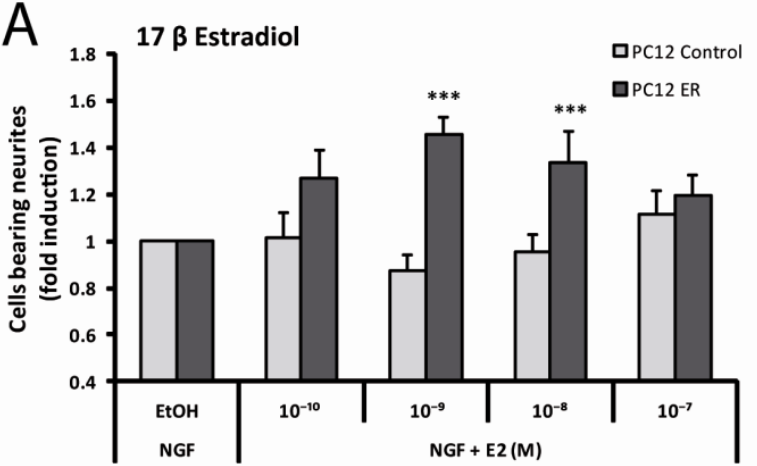

C

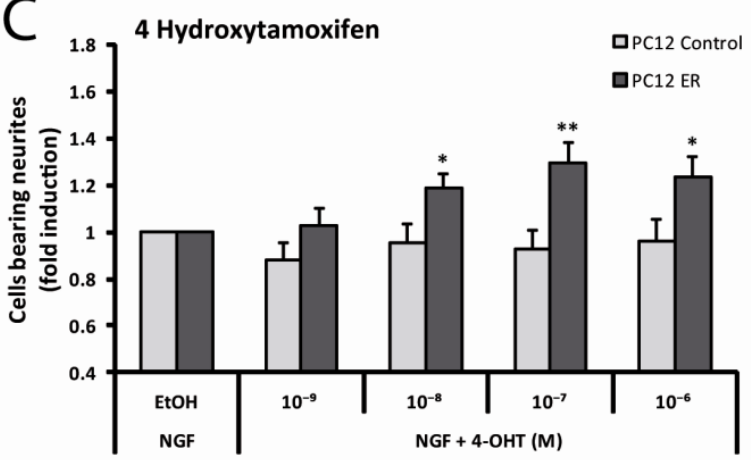

E

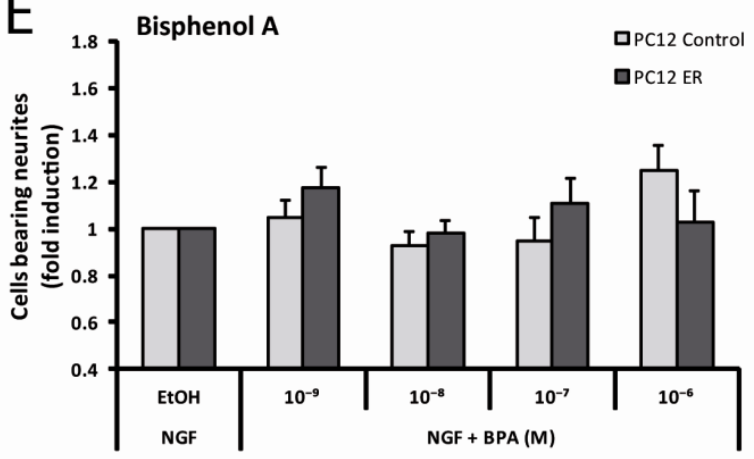

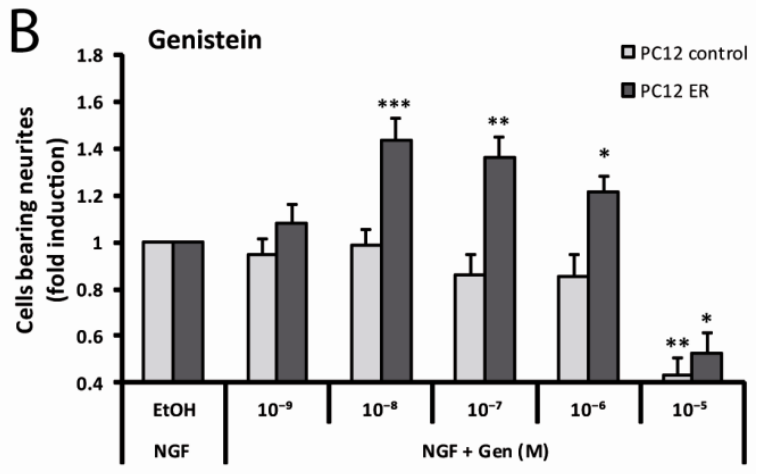

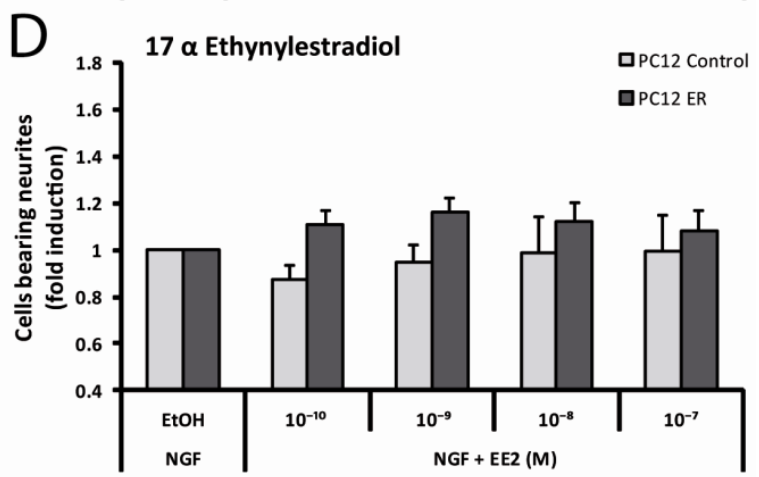

F

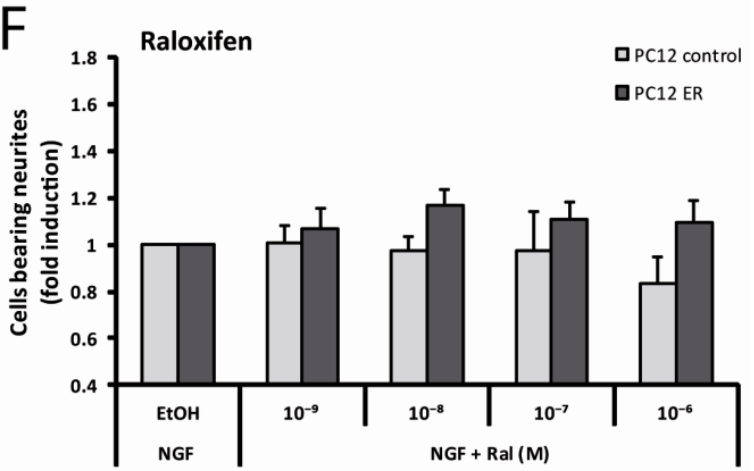

